\title{
Flotation techniques to improve viability of Juniperus polycarpos seed lots
}

\author{
Abolfazl Daneshvar ${ }^{1,2} \cdot$ Mulualem Tigabu $^{1} \cdot$ Asaddollah Karimidoost $^{3}$. \\ Per Christer Odén ${ }^{1}$
}

Received: 16 February 2016/Accepted: 18 March 2016/Published online: 12 September 2016

(c) The Author(s) 2016. This article is published with open access at Springerlink.com

\begin{abstract}
The germination of freshly collected Juniperus polycarpos (K. Koch) seeds is very low and attributed to the large proportion of nonviable seeds in the seed lots. Thus, the aim of this study was to improve seed lot quality by removing nonviable seeds using two flotation techniques: incubation-drying-separation (IDS) and modified specific gravity (MSG) separation. We examined different IDS conditions (the specific incubation time, subsequent drying time and sorting media) for effectively sorting out nonviable seeds; and tested the feasibility of modified SG separation, which involved soaking seeds in water for a certain period before sorting in different concentrations of sucrose solution. Viable seeds were expected to absorb and metabolically bind more water during soaking than dead seeds could, and hence be sorted effectively depending on the viscosity of the sucrose solution. The viability of the seeds that floated or sank was determined in a topographical tetrazolium chloride (TTC) test. For the IDS trial,
\end{abstract}

Project funding: The first author is financially supported by the Iranian government scholarship program.

The online version is available at http://www.springerlink.com.

Corresponding editor: Yu Lei.

Mulualem Tigabu

Mulualem.Tigabu@slu.se

1 Southern Swedish Forest Research Centre, Swedish University of Agricultural Sciences, P.O. Box 49, SE-230 53 Alnarp, Sweden

2 Department of Natural Resources, Gonbad Kavoos University, Shahid Fallahi Street, P.O. Box 163, Gonbad, Iran

3 Agriculture and Natural Resources Research Center of Golestan Province, Beheshti Ave., P.O. Box 4915677555, Gorgan, Iran
7 days incubation followed by $9 \mathrm{~h}$ of drying and sedimentation in pure water or $200 \mathrm{~g} \cdot \mathrm{L}^{-1}$ sucrose solution identified, respectively, 75 and $82 \%$ of the seeds as viable (sunken) seeds. For the MSG trail, $77 \%$ viable seeds were recovered in the sunken fraction when seeds were soaked for $48 \mathrm{~h}$ then immediately sorted in $600 \mathrm{~g} \cdot \mathrm{L}^{-1}$ sucrose solution. In both cases, the loss of viable seeds in the discarded floating fraction was only $4 \%$. The results demonstrate that both IDS and MSG separation techniques substantially improved seed lot viability, but MSG separation is simple and needs no modern seed handling facility, and its efficacy relies on seed mass (due to the initial soaking) and the specific density and viscosity of the flotation medium.

Keywords Incubation-drying-separation (IDS) · Iran · Juniperus polycarpos - Specific gravity (SG) separation · Seed viability $\cdot$ Seed sorting system

\section{Introduction}

Juniperus polycarpos (K. Koch) is one of the dominant juniper species with a wide geographic distribution, ranging from central and western Asia as far as the Near East and western China (Adams 2014). In Iran, the species occurs naturally along the southern slopes of the Alborz mountain chain and the northern part of Khorasan at altitudes from 750 to $3400 \mathrm{~m}$ above sea level (Korouri et al. 2012). Over the past several decades, the juniper forests have been greatly degraded by anthropogenic disturbances, coupled with poor natural regeneration and poor growth conditions (low winter temperature, poor soil conditions and summer drought). In Iran, the area of $J$. polycarpos forest has been reduced from an estimated 1.2 million ha in 
the early 1970s (Djavanshir 1974) to approximately 0.5 million ha by the early 2000s (Kharazipour et al. 2008). Owing to the immense economic and ecological importance of juniper forests (Okasaka et al. 2006; Akkol et al. 2009; Korouri et al. 2012), interests in conserving and restoring degraded juniper forests have been continuously growing. In Iran, for instance, commercial harvesting of $J$. polycarpos has been prohibited since 1989, and protected areas have been established to reduce anthropogenic disturbances. However, passive restoration-relying on natural regeneration alone-has been insufficient due to long seed production cycle (seed mast year every 4-8 years) and poor seed lot quality (Ahani et al. 2013).

The germination of $J$. polycarpos seed lots is reported to be very low; ca. $12 \%$ of seeds are collected at the right time (Khoushnevis et al. 2008). The poor germination is thought to be due to poor seed lot quality and dormancy (Ahani et al. 2013). Commonly, large proportions of the collected seeds are nonviable (empty, shriveled, and anatomically underdeveloped seeds). The large quantity of empty and dead seeds collected from many conifers, including junipers, is due to pollination failures, underdevelopment of female gametophytes, degeneration of male gametophytes and/or post-zygotic degeneration during the various stages of embryogenesis (Slobodník and Gutternberger 2000; Sivakumar et al. 2007; Ahani et al. 2013). In addition, up to $58 \%$ of mature juniper fruits are attacked by Megastigmus insect species, resulting in germination failure (Djavanshir 1974). These unproductive seeds should be removed from the seed lots to produce the desired quantity of seedlings needed for active restoration program and for ensuring a high percentage of usable seeds in nurseries (Himanen and Nygren 2015) to reduce the cost of containerized seedling production.

Specific gravity (SG) and incubation-drying-separation (DS) are two widely used sorting techniques to remove nonviable seeds from a given seed lot. For instance, using petroleum ether for SG separation, Sivakumar et al. (2007) improved the germination of Casuarina equisetifolia Forst seed lots to $90 \%$, Falleri and Pacella (1997) achieved $61 \%$ for Platanus $\times$ acerifolia (Ait.) Willd seed lot. Using SG separation in water, Himanen and Nygren (2015) effectively sorted nonviable seeds of Picea abies L. (Karst.), and Demelash et al. (2003) achieved $84 \%$ germination.

IDS is another successful sorting technique for culling dead-filled seeds to improve seed lot quality of conifers (Simak 1984; Downie and Wang 1992; Poulsen 1995; Demelash et al. 2002) and broad-leaved species (Falleri and Rosetta 1997; Demelash et al. 2003). The principle behind the IDS technique is that when imbibed seeds are incubated for a certain period before being uniformly dried, the dead-filled and empty seeds lose moisture more rapidly than the live seeds do, and hence separate from the viable ones in flotation media. However, the sorting efficiency of IDS technique varies among species and seed lots; thus, the optimal IDS conditions for any new species have to be determined empirically.

The seed lots used in the present study had $13 \%$ initial moisture content, and after the SG separation, all floaters were empty or insect-damaged seeds. However, when the sunken seeds were assessed for viability in tetrazolium chloride (TTC) and cutting tests, only $48 \%$ of the sunken seeds were viable. Thus, $52 \%$ of the sunken seeds were still nonviable and needed further sorting by other techniques. To our knowledge, no information has been documented about the application IDS technique to improve the quality of $J$. polycarpos seed lots. Thus, the main objectives of the present study were (1) to determine the optimal IDS condition (the specific incubation time, subsequent drying time and sorting media) for effective separation of nonviable seeds and (2) to test the feasibility of modified SG separation in sucrose solution as alternative sorting technique to IDS. The modified SG separation involved soaking seeds in water for a certain time before sorting. Viable seeds were expected to absorb and metabolically bind more water during soaking than could dead seeds (seeds with a mass of undifferentiated, wrinkled, black tissue). Depending on the viscosity of the sucrose solution, which influences the movement of the seeds through the solution, viable and dead seeds were sorted effectively.

\section{Materials and methods}

\section{Seed collection and processing}

Fully mature cones were collected from a J. polycarpos stand at Chaharbagh in the Alborz Mountains in northeastern Iran, located between $36^{\circ} 36^{\prime}-36^{\circ} 41^{\prime} \mathrm{N}$ and $54^{\circ} 28^{\prime}-$ $54^{\circ} 35^{\prime} \mathrm{E}$ at altitudes ranging from $2400-2500 \mathrm{~m}$ above sea level. Cones were collected from 20 healthy trees $(2 \mathrm{~kg}$ per tree) that were $100 \mathrm{~m}$ apart to capture as much genetic variability as possible. Cones were picked from all accessible branches of each sample tree to ensure representative seed samples and to avoid the effect of cone position in the crown on seed viability (Mamo et al. 2006). In the laboratory, seeds were extracted manually by rubbing cones that were macerated for $48 \mathrm{~h}$ between two pieces of screening mesh. The seeds were further soaked and stirred in limewater for removing the remaining pulp from the seeds. According to current practice for sorting empty seeds in Iran, seeds were placed in a bowl containing Millipore-filtered water and stirred to facilitate separation. The floating and sunken fractions were collected separately 
after $5 \mathrm{~min}$. The floating seeds (empty and insect-damaged seeds) were discarded; the sunken fraction (viable and dead seeds) were air-dried at room temperature for 1 week to reduce the original $13 \%$ moisture content to the desired storage moisture content (ca. $6 \%$ ). The seeds were then packed in plastic bags, sealed and stored in the refrigerator at $5{ }^{\circ} \mathrm{C}$ until use.

Because seed coats of $J$. polycarpos contain high amounts of resin, the importance of cleaning resin for seed imbibition was first assessed by cleaning a batch of seeds with acetone for $2 \mathrm{~min}$, rinsing with running tap water, then imbibing seeds with and without resin in plastic boxes with $400 \mathrm{~mL}$ water for $72 \mathrm{~h}$ at room temperature $\left(20^{\circ} \mathrm{C}\right)$. Every $24 \mathrm{~h}$, the moisture content of the seeds was determined after quickly surface-drying the seeds with a paper towel. The test showed that seeds with resins absorbed water slower than resin-cleaned seeds did; and the moisture content reached $30 \%$ after $72 \mathrm{~h}$ (Fig. 1). This level of moisture content has been proven useful for sorting viable and nonviable seeds of several conifer species using the IDS technique. Thus, resin-cleaned seeds were used in the subsequent sorting experiments, and the moisture content of the seeds was adjusted to $30 \%$ before incubation for the IDS experiment. Unlike the original IDS technique in which the amount of water reaching $30 \%$ moisture content is added at the start of incubation, our approach ensures that the seeds start with the desired moisture content, thus allowing more time for the viable seeds to metabolically bind the water in their tissue.

\section{IDS experiments}

In a series of IDS experiments, the effects of drying time, flotation media and incubation period on sorting efficiency of viable from nonviable seeds were determined. In the first

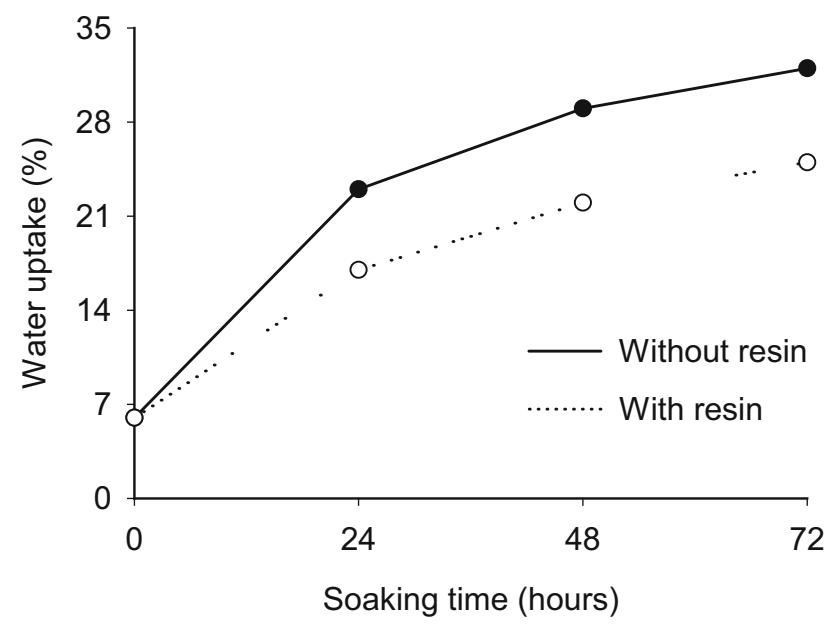

Fig. 1 Time course of water uptake by Juniperus polycarpos seeds with and without resin on the surface of the seed coat experiment, the effect of drying time on sorting efficient in water was investigated. For this purpose, seeds pre-imbibed to $30 \%$ moisture content were placed in plastic incubation tubes and left in a climate chamber set at $15{ }^{\circ} \mathrm{C}$ and ca. $85 \%$ relative humidity for 7 days. Each incubation tube was capped with a one-way polytetrafluoroethylene membrane (Goretex ${ }^{\mathrm{TM}}$ ) that allows gas exchange but not water. Every day, moisture content of the seeds was checked and adjusted as deemed necessary. After 7 days of incubation, seeds were evenly distributed on a piece of netted cloth and dried in a fan-ventilated drying cabinet at $20{ }^{\circ} \mathrm{C} \pm 2{ }^{\circ} \mathrm{C}$ and ca. $40 \%$ relative humidity for 3, 6, 9, 12 and $15 \mathrm{~h}$. Immediately after drying, seeds were placed in a bowl containing Millipore-filtered water, stirred to facilitate sedimentation of the seeds, and the floating and sunken seeds were collected separately after $5 \mathrm{~min}$.

In the second experiment, the effect of sorting media on sorting efficiency of the IDS technique was investigated in two steps. First, 7-day-incubated seeds that were dried for $9 \mathrm{~h}$ were put in different sucrose solutions $(0,100,150$, 200 , and $250 \mathrm{~g} \cdot \mathrm{L}^{-1}$ water), and the floating and sunken seeds were collected separately after 5 min with intermittent stirring to facilitate sedimentation of the seeds. In the second step, the effect of different drying times (3, 6, 9, 12 and $15 \mathrm{~h}$ ) on sorting of viable and nonviable seeds in $200 \mathrm{~g} \cdot \mathrm{L}^{-1}$ sucrose solution based on results of the previous experiment was examined. The third experiment compared the sorting efficiency of the 3- and 7-day incubation when followed by $9 \mathrm{~h}$ drying, then sorting in $200 \mathrm{~g} \cdot \mathrm{L}^{-1}$ sucrose solution to determine whether a shorter incubation was as good as the longer incubation. For all IDS experiments, four replications of 100 resin-cleaned seeds were used.

\section{Modified SG experiment}

To examine whether SG separation in sucrose solution could be a simple alternative to IDS technique, we designed a factorial experiment with three soaking times and six concentrations of sucrose solutions. Before the sorting experiment, seeds were placed in plastic boxes filled with $400 \mathrm{~mL}$ water and left to imbibe for 24,48 and $72 \mathrm{~h}$ at $20^{\circ} \mathrm{C}$. After each soaking time, seeds were immediately placed in bowls containing $0,100,200,400$, 600,800 or $1000 \mathrm{~g} \cdot \mathrm{L}^{-1}$ sucrose solutions. After $5 \mathrm{~min}$ of intermittent stirring to facilitate sedimentation, the floating and sunken seeds were collected separately. For each treatment, four replications of 100 resin-cleaned seeds were used.

\section{Assessment of seed viability}

Since juniper seeds, including $J$. polycarpos, are dormant (Baskin and Baskin 1998) and a dormancy-breaking 
method is not yet known for this species, the viability of floating and sunken seeds was determined by a TTC test, which is a standardized, internationally accepted biochemical test for seed viability (International Seed Testing Association 2010). In principle, when seeds are soaked in a colorless, soluble 2,3,5-triphenyl tertrazolium chloride solution for a given time in darkness, viable seeds convert the compound into a stable and non-diffusible red compound (2,3,5 triphenyl formazan); hence, viable and nonviable seeds can be differentiated by the red staining. For juniper species, the recommended test involves premoistening the seeds at $20{ }^{\circ} \mathrm{C}$ for $18 \mathrm{~h}$, cutting transversely $1 / 3$ from the distal end to open embryo cavity, immersing the seeds in $1 \%$ staining solution for $18 \mathrm{~h}$ in darkness, and finally cutting longitudinally through the endosperm to expose the embryo to check for staining. In this study, dry seeds were soaked in water for $24 \mathrm{~h}$ to make sure that the seeds were sufficiently softened for ready puncturing and even staining. The number of red-stained, viable seeds in floating and sunken fractions was then recorded.

\section{Analysis of dehydration rate and seed mass of viable and nonviable seeds}

For insights into the underlying mechanism that allows differentiation of viable and nonviable seeds of $J$. polycarpos, seed mass and the rate of dehydration of viable and nonviable seeds were examined in retrospect to the viability determinations in the separations experiments. For determining seed mass, four replicates of 100 viable and 100 nonviable seeds were used. For examining the dehydration rate, viable and nonviable seeds were incubated separately for 7 days and dried for 3, 6, 9, 12 and $15 \mathrm{~h}$ as described already. The moisture content of seeds for each drying time was determined on a dry basis.

\section{Statistical analyses}

The percentage of viable seeds in floating and sunken fractions was calculated separately as the ratio of the number of viable seeds in the $i$ th fraction to the total number of seeds in the $i$ th fraction multiplied by 100 . Sorting efficiency, defined as the overall gain in viable seeds after sorting, was computed as the difference in proportion of viable seeds in the sunken fraction to that of the discarded floating fraction. Because seed viability has a binomial distribution (Zar 1996), percentage viability was arcsine-transformed to meet the assumptions of homoscedasticity and normal distribution. For the IDS experiment, a one-way ANOVA was performed to examine the effect of different drying times, and concentrations of sucrose solution on the proportion of viable seeds in the floating and sunken fractions and the sorting efficiency. For the SG experiment, a two-way ANOVA was used to examine the effects of soaking time and different concentrations of sucrose solution on the proportion of viable seeds in each seed lot fraction and on overall sorting efficiency. Means that differed significantly were compared using Tukey's test at $5 \%$ level of significance. An independent-sample $t$ test was used to compare differences in the proportion of viable seeds in each seed lot fraction and in sorting efficiency after 3 and 7 days of incubation. All data analyses were performed with Minitab 17.0 statistical software (Minitab Inc., State College, PA, USA).

\section{Results}

\section{IDS technique to sort viable from nonviable seeds}

The results showed significant differences $(p<0.001$ in both cases) in the number of floating and sunken seeds with respect to drying times tested. As drying time increased, the number of floating seeds increased, and the sunken seeds decreased linearly (Fig. 2a). No viable seeds were found after $3 \mathrm{~h}$ of drying in the floating fraction, but the share of viable seeds in the floating fraction was significantly lower $(p<0.01)$ after 6 and 9 h of drying than after $12 \mathrm{~h}$, which in turn yielded significantly more viable seeds than did $15 \mathrm{~h}$ of drying (Fig. 2b). For the sunken fraction, the proportion of viable seeds was significantly higher ( $p=0.01$ ) after 9 and $12 \mathrm{~h}$ of drying than after the other drying times tested. As a whole, $9 \mathrm{~h}$ of drying appeared to be most efficient in terms of the net gain of viable seeds after sorting, while $15 \mathrm{~h}$ of drying was the least efficient (Fig. 2c).

With regard to sorting media, significant differences in number of floating and sunken seeds and the proportion of viable seeds in each seed lot fraction were detected among different concentrations of sucrose solution $(p<0.01)$. The number of floating seeds ranged from $38 \%$ in pure water $\left(0 \mathrm{~g} \cdot \mathrm{L}^{-1}\right)$ to $55 \%$ in $250 \mathrm{~g} \cdot \mathrm{L}^{-1}$ sucrose solution, whereas the proportion of sunken seeds ranged from $62 \%$ in pure water to $45 \%$ in $250 \mathrm{~g} \cdot \mathrm{L}^{-1}$ sucrose solution (Fig. 3a). The proportion of viable seeds in the floating fraction was less than $5 \%$ for pure water and all other concentrations of sucrose solutions tested except in $250 \mathrm{~g} \cdot \mathrm{L}^{-1}$, which yielded more viable seeds than in the floating fractions (Fig. 3b). For the sunken fraction, the proportion of viable seeds was the highest ( $82 \%$ ) in $200 \mathrm{~g} \cdot \mathrm{L}^{-1}$ sucrose solution compared with pure water and low concentrations of sucrose solution (Fig. 3c). The net gain in viable seeds after sorting (overall sorting efficiency) did not vary significantly $(p=0.173)$ among concentrations of the sorting media, albeit, $200 \mathrm{~g} \cdot \mathrm{L}^{-1}$ tended to yield higher gains (Fig. 3c). 

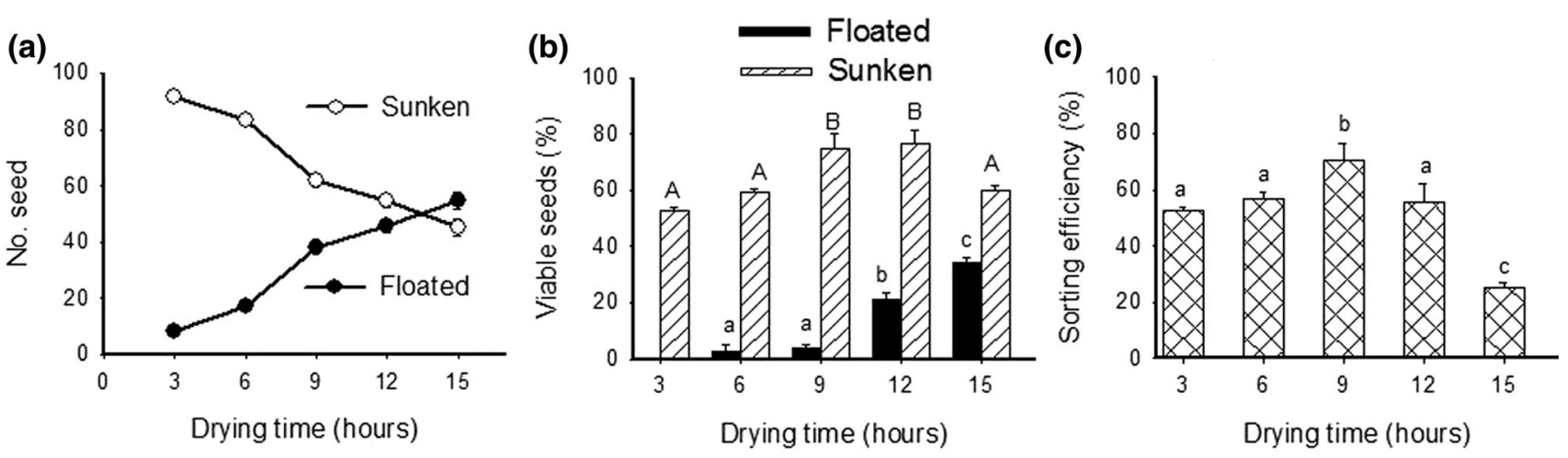

Fig. 2 Number of seeds recovered in the floated and sunken fractions (a), their corresponding proportion of viable seeds (b) and overall

(mean $\pm \mathrm{SE}$ ). For each seed lot fraction, bars with different letters are sorting efficiency (c) of IDS in water and different drying times

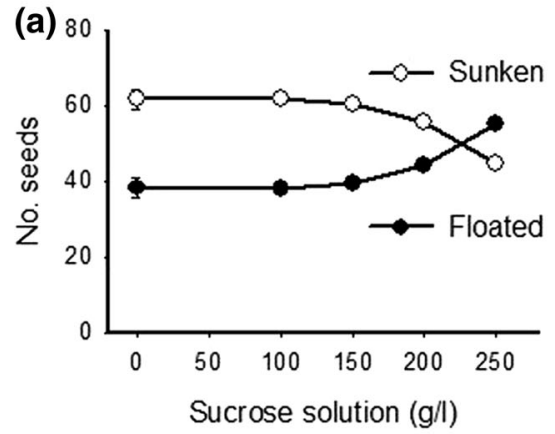

Fig. 3 Number of seeds recovered in the floated and sunken fractions (a), their corresponding proportion of viable seeds (b) and overall sorting efficiency (c) of IDS in different concentrations of sucrose

In the test of different drying times on the efficacy of IDS in $200 \mathrm{~g} \cdot \mathrm{L}^{-1}$ sucrose solution, the proportion of viable seeds in floating and sunken fractions and the overall sorting efficiency differed significantly $(p<0.01)$. Fewer viable seeds were found in the floating fraction after 3,6 , and $9 \mathrm{~h}$ of drying than after longer drying times (12 and $15 \mathrm{~h}$ ), whereas fewer viable seeds were found in the sunken fraction after 3 and $6 \mathrm{~h}$ of drying than after the other drying times (Table 1). The overall sorting efficiency of IDS in $200 \mathrm{~g} \cdot \mathrm{L}^{-1}$ sucrose solution was highest $(78 \%)$ after $9 \mathrm{~h}$ drying and lowest (53\%) after $15 \mathrm{~h}$ (Table 1).

The independent-sample $t$-test to compare sorting efficiency after 3 and 7 days of incubation revealed that the proportion of viable seeds recovered in the sunken fraction was significantly higher $(p=0.011)$ after the 7-day incubation than after 3 before $9 \mathrm{~h}$ of drying and sorting in $200 \mathrm{~g} \cdot \mathrm{L}^{-1}$ sucrose solution (Table 2 ). In floating fractions, the proportion of viable seeds was much lower than in the sunken viable seed fraction, and was the same for both incubation periods. As a whole, the sorting efficiency was significantly higher after 7 days incubation $(80 \%)$ than after $3(71 \%)$.

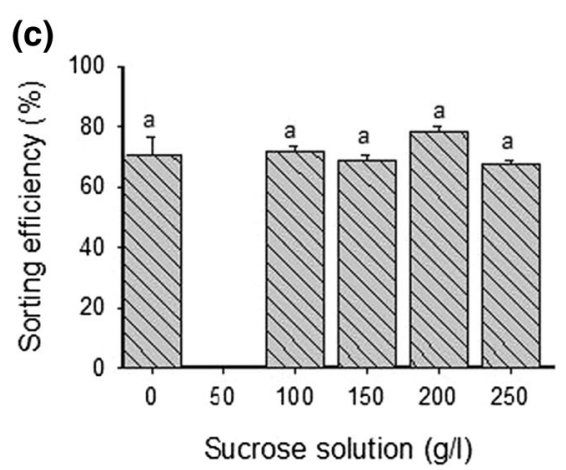

solution as sorting media (mean $\pm \mathrm{SE}$ ). For each seed lot fraction, bars with different letters are significantly different $(p<0.05)$

Table 1 Proportion of viable seeds in floated and sunken fractions for IDS treatment that involved 7 days of incubation, different drying times and sorting in $200 \mathrm{~g} \cdot \mathrm{L}^{-1}$ sucrose solution (mean $\pm \mathrm{SE}$ )

\begin{tabular}{lccl}
\hline Drying time (h) & \multicolumn{2}{l}{ Proportion of viable seeds (\%) } & Sorting efficiency \\
\cline { 2 - 3 } & Floated & Sunken & \\
\hline 3 & $0 \pm 0 \mathrm{a}$ & $61 \pm 2 \mathrm{a}$ & $61 \pm 2 \mathrm{~b}$ \\
6 & $2 \pm 1 \mathrm{a}$ & $65 \pm 3 \mathrm{a}$ & $63 \pm 2 \mathrm{~b}$ \\
9 & $4 \pm 1 \mathrm{a}$ & $82 \pm 1 \mathrm{~b}$ & $78 \pm 2 \mathrm{c}$ \\
12 & $20 \pm 2 \mathrm{~b}$ & $84 \pm 1 \mathrm{~b}$ & $64 \pm 3 \mathrm{~b}$ \\
15 & $30 \pm 2 \mathrm{c}$ & $83 \pm 1 \mathrm{~b}$ & $53 \pm 3 \mathrm{a}$
\end{tabular}

Means followed by the same letter(s) across each column are not significantly different at $5 \%$ probability level

\section{MSG separation of viable and nonviable seeds}

Soaking seeds for 24,48 and $72 \mathrm{~h}$ increased the moisture content to 23,29 and $32 \%$, respectively. The SG separation of viable and nonviable seeds of J. polycarpos showed significant variations among pre-sorting soaking times, 
Table 2 Effect of incubation period on the proportion of viable seeds recovered in the floated and sunken fraction following IDS in $200 \mathrm{~g} \cdot \mathrm{L}^{-1}$ sucrose solution (mean $\pm \mathrm{SE})$

\begin{tabular}{llll}
\hline Incubation period (day) & \multicolumn{2}{l}{ Proportion of viable seeds $(\%)$} & Sorting efficiency \\
\cline { 2 - 3 } & Floated & Sunken & \\
\hline 3 & $1 \pm 1$ & $71 \pm 2$ & $70 \pm 2$ \\
7 & $4 \pm 1$ & $82 \pm 1$ & $80 \pm 1$ \\
$t$-Value $(\mathrm{df}=4)$ & 2.30 & 4.50 & 3.53 \\
$\mathrm{p}$-Value & 0.070 & 0.011 & 0.024 \\
\hline
\end{tabular}

Note that for both incubation periods, the seeds were dried for $9 \mathrm{~h}$ before sorting
Fig. 4 SG separation of Juniperus polycarpos seed lot using different pre-sorting soaking times and different concentrations of sucrose solutions as sorting medium (mean $\pm \mathrm{SE}$ ). For each soaking time and seed lot fraction, bars with different letters are significantly different $(p<0.05)$
24 hrs. soaking
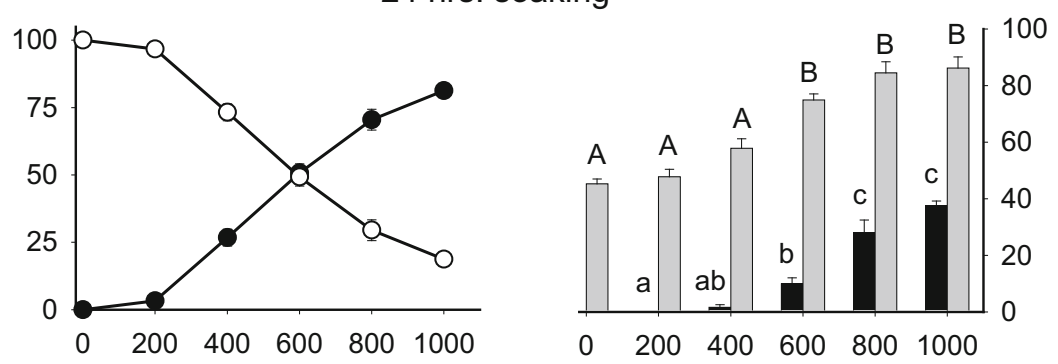

$48 \mathrm{hrs}$. soaking
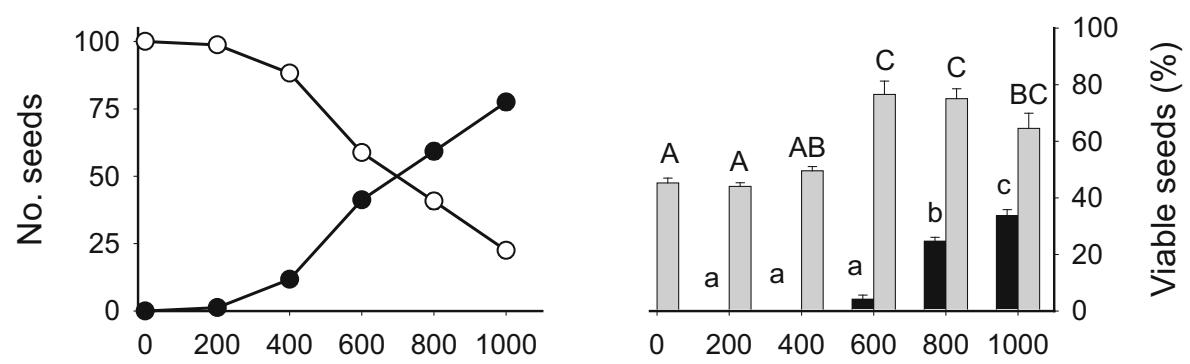

72 hrs. soaking

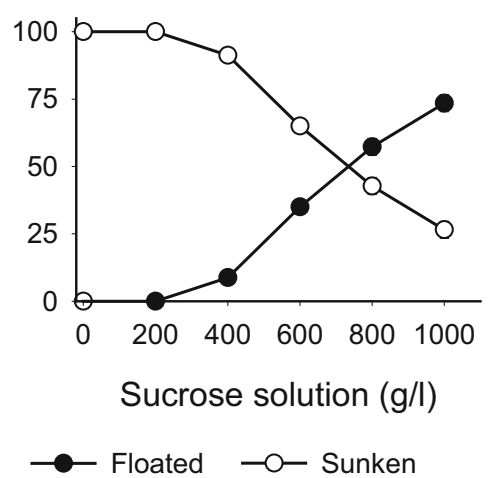

Sucrose solution $(\mathrm{g} / \mathrm{l})$

Floated $\rightleftharpoons$ Sunken concentrations of the sorting medium and their interaction ( $p<0.01$ in all cases). As the concentration of sucrose solution increased from $0 \mathrm{~g} \cdot \mathrm{L}^{-1}$ (pure water) to $250 \mathrm{~g} \cdot \mathrm{L}^{-1}$, the proportion of floating seeds increased, while the proportion of sunken seeds decreased continuously irrespective of the pre-sorting soaking time, although the decrease or increase was sharp for seeds soaked for $24 \mathrm{~h}$ (Fig. 4). At lower concentrations of sucrose solution $(0$ and
$200 \mathrm{~g} \cdot \mathrm{L}^{-1}$ ), all seeds sunk irrespective of the soaking times tested.

For seeds soaked for $24 \mathrm{~h}$ before sorting, $\mathrm{SG}$ separation in higher concentration of sucrose solution $\left(\geq 600 \mathrm{~g} \cdot \mathrm{L}^{-1}\right)$ returned more viable seeds in the sunken fraction than lower concentrations (200-400 $\left.\mathrm{g} \cdot \mathrm{L}^{-1}\right)$ and pure water; whereas the proportion of viable seeds in the floating fraction was larger when very high concentrations of sucrose solution 
were used as sorting medium $\left(800-1000 \mathrm{~g} \cdot \mathrm{L}^{-1}\right)$ than moderate $\left(600 \mathrm{~g} \cdot \mathrm{L}^{-1}\right)$ and low concentrations; particularly no viable seed was recorded for pure water and $200 \mathrm{~g} \cdot \mathrm{L}^{-1}$ sucrose solution (Fig. 4). While SG separation using 600 and $800 \mathrm{~g} \cdot \mathrm{L}^{-1}$ sucrose solutions resulted in more viable seeds in the sunken fraction after $48 \mathrm{~h}$ of soaking than with lower concentrations of sucrose, more viable seeds were recovered in the sunken fraction than in very high concentrations (800-1000 g. $\mathrm{L}^{-1}$ ) with $72 \mathrm{~h}$ of soaking (Fig. 4). As a whole, the efficiency of SG separation was best when seeds were soaked for $48 \mathrm{~h}$ and then sorted using $600 \mathrm{~g} \cdot \mathrm{L}^{-1}$ sucrose solutions, bringing the net gain of viable seeds in the sunken fraction to $72 \%$ (Fig. 5).

\section{Seed mass and dehydration rate}

For insights into the sorting efficiency of IDS technique, the seed mass of viable and nonviable seeds were then determined; and the results showed that viable seeds were significantly $[t(4)=6.38, p=0.03]$ heavier than nonviable seeds (Fig. 6a). For dehydration rates comparisons, the viable seeds dried slower than the nonviable seeds, and the dehydration rate was very fast for nonviable seeds during the first $3 \mathrm{~h}$ of drying (Fig. 6b).

\section{Discussion}

Seed lots of $J$. polycarpos contain a large quantity of empty and dead seeds, which could be attributed to asynchronous maturation of female and male flowers, unsuitable climatic conditions and mistletoe infection (Djavanshir 1974;

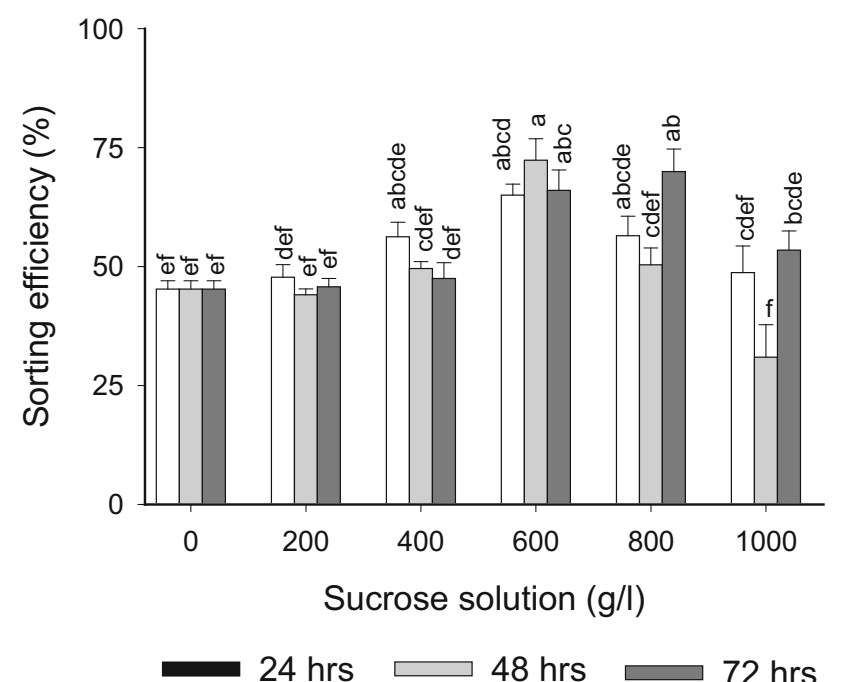

Fig. 5 Overall sorting efficiency of SG in different concentrations of sucrose solution and soaking times (mean $\pm \mathrm{SE}$ ). Bars with different letters are significantly different $(p<0.05)$
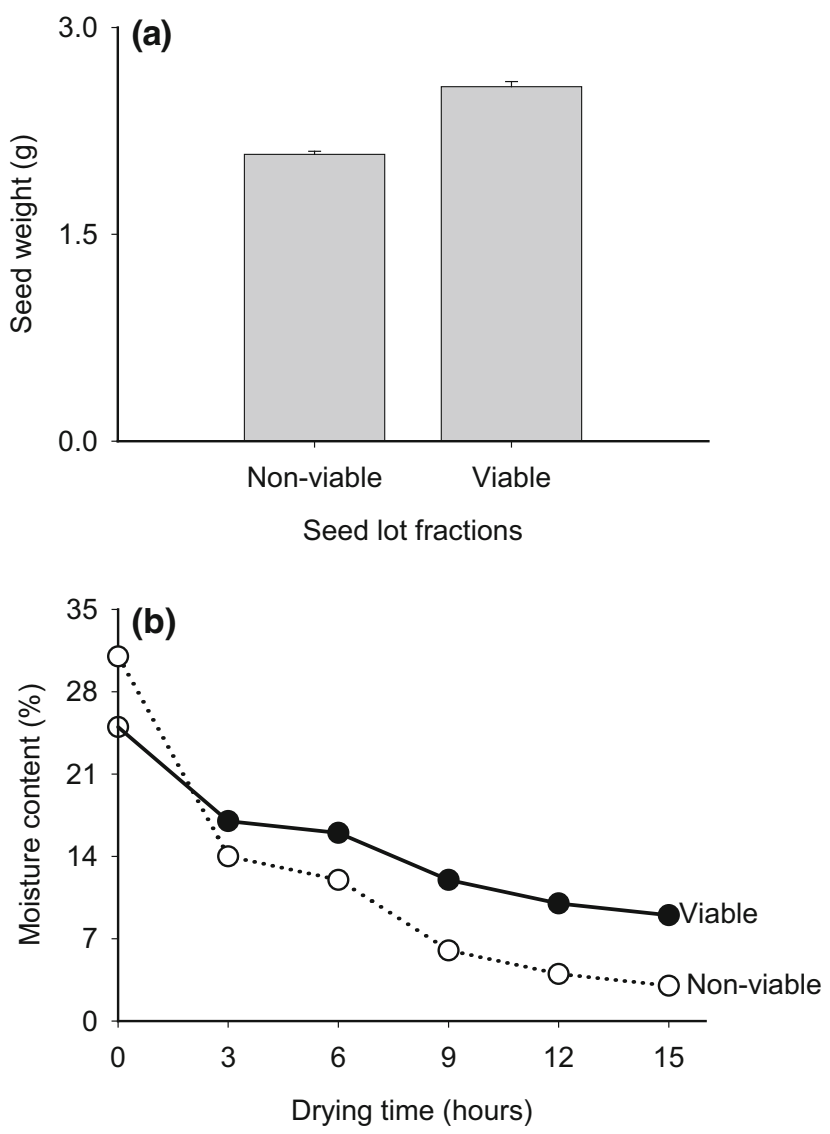

Fig. 6 Seed weight (a) and dehydration rate (b) of viable and nonviable seeds of Juniperus polycarpos

Daneshvar et al. 2014). Female flowers appear in early spring; meanwhile, the male strobili have been forming since the previous summer, so that pollen can be released a few days after the female strobili become receptive (10-12 days after which the cone scales close). This short pollination period may contribute to the production of a large quality of empty seeds due to pollination failure. In addition, environmental factors during seed development have a strong influence on seed filling, thereby accounting for the production of empty and dead seeds (Wulff 1995; Gutterman 2000). Temperature extremes may also alter the duration of ovule exposure (openness) and opening of male strobili, while high humidity in early mornings produces water droplets that facilitate pollen transfer.

The present study revealed that these nonviable seeds (mainly dead seeds) can be removed from the seed lot by IDS and modified SG separation techniques once the empty and insect-damaged seeds are sorted using the conventional flotation technique. The IDS conditions tested in the present study substantially improved the quality of the $J$. polycarpos seed lot from $48 \%$ to more than $75 \%$. Among the IDS conditions tested in the present study, a 7-day incubation followed by $9 \mathrm{~h}$ of drying, then sorting in 
either water (75\% viable seeds; Fig. 2) or $200 \mathrm{~g} \cdot \mathrm{L}^{-1}$ sucrose solution ( $82 \%$ viable seeds; Table 1 and Fig. 3) were effective in terms of yielding a high proportion of viable seeds in the sunken fraction and low in the discarded floating fraction (4\%). Compared with the 3-day incubation originally used by Simak (1981), 7 days allows viable seeds to metabolically bind the absorbed water and thus to dry slowly during the drying process (Fig. 6). The fact that the proportion of viable seeds in the floating fraction increased with drying time is attributed to loss of moisture from viable but low vigor seeds during the extended drying (e.g. 15 and $12 \mathrm{~h}$ ), as found for other species (e.g., Demelash et al. 2003).

In the present study, IDS in $200 \mathrm{~g} \cdot \mathrm{L}^{-1}$ sucrose solution resulted in the recovery of more viable seeds in the sunken fraction than the IDS in water (Fig. 3). Thus, the sorting efficiency depends not only on the specific density of the sorting medium but also on its viscosity (a measure of the extent to which a fluid opposes the movement of an object through it). At a given temperature, the higher the concentration of the solution, the higher the viscosity will be and the less the object will move through the solution. At $20{ }^{\circ} \mathrm{C}$, the specific density and viscosity of $200 \mathrm{~g} \cdot \mathrm{L}^{-1}$ sucrose solution are $1.081 \mathrm{~g} \cdot \mathrm{L}^{-1}$ and $1.941 \mathrm{mPa} \cdot \mathrm{s}$, respectively; whereas pure water has a specific density of $1 \mathrm{~g} \cdot \mathrm{L}^{-1}$ and a viscosity of $1.002 \mathrm{mPa} \cdot \mathrm{s}$. Thus, the rate of sedimentation of seeds decreases with increasing viscosity of the sucrose solution, as evidenced from the low number of seeds that sank with increasing concentration of the sucrose solution in the IDS experiment (Fig. 3). A similar result was found for SG separation in different concentrations of sucrose solution (Fig. 4). However, $48 \mathrm{~h}$ of soaking followed by separation in $600 \mathrm{~g} \cdot \mathrm{L}^{-1}$ sucrose solution results in a sorting efficiency comparable to the IDS technique. This result underscores the feasibility of SG separation as a simple alternative to the IDS technique, particularly for local nurseries where modern facilities for IDS (such as a controlled climate chamber, appropriate drier) are not readily available.

Although the proportion of viable seeds lost in the discarded floating fraction was low for the best IDS and SG separations tested in the present study, 20-24\% of the seeds in the sunken fraction were still nonviable, an undesirable level for nursery seedling production. These results might be due to the common size variation among individual seeds in juniper seed lots (Mamo et al. 2006; Daneshvar et al. 2014). Although the average seed mass of viable seeds is greater than that of nonviable seeds (Fig. 6), some of the nonviable seeds could be larger and heavier and thus sink with the viable seeds, while small, viable seeds with low vigor continue to float. As a result, the sorting efficiency is below the hypothetical maximum of $100 \%$ as previously reported for several species (Sweeney et al. 1991; Downie and Wang 1992; Poulsen 1995; Falleri and Rosetta 1997; Demelash et al. 2002, 2003; Pasquini et al. 2008).

\section{Conclusion}

The low germination performance of $J$. polycarpos seed lot can be attributed to the large quantity of nonviable seeds in the sunken fraction even after the conventional SG separation in water. Such unproductive seeds can be effectively removed either (1) by incubating imbibed seeds for 7 days, drying them for $9 \mathrm{~h}$ and sorting them in water or $200 \mathrm{~g} \cdot \mathrm{L}^{-1}$ sucrose solution or (2) by soaking seeds in water for $48 \mathrm{~h}$ and then sorting them in $600 \mathrm{~g} \cdot \mathrm{L}^{-1}$ sucrose solution. These sorting conditions minimize the loss of viable seeds in the discarded floating fraction (4\%). Thus, nurseries can further improve the quality of $J$. polycarpos seed lots obtained through current nursery practice by conventional SG separation in water, which only sorts out empty and insect-damaged seeds, to $75-82 \%$ by adopting IDS or MSG separation techniques, depending on their facilities. For further improving sorting efficiency, testing drying times between 9 and $12 \mathrm{~h}$ and concentration of sucrose solution between 200 and $250 \mathrm{~g} \cdot \mathrm{L}^{-1}$ (IDS) and manipulating the concentrations between 600 and $800 \mathrm{~g} \cdot \mathrm{L}^{-1}$ (MSG) is worth investigating. Because the genus Juniperus (Cupressaceae) consists of approximately 67 species that are mostly distributed over the northern hemisphere (Farjon 2005) with a known seed lot quality problem, the results from this study will provide a baseline for improving seed lot performance of other juniper species.

Acknowledgments The authors thank the employees of Iranian Agricultural and Natural Resources Research Center (Golestan Province) for their help during seed collection.

Open Access This article is distributed under the terms of the Creative Commons Attribution 4.0 International License (http://creative commons.org/licenses/by/4.0/), which permits unrestricted use, distribution, and reproduction in any medium, provided you give appropriate credit to the original author(s) and the source, provide a link to the Creative Commons license, and indicate if changes were made.

\section{References}

Adams RH (2014) Junipers of the World: the genus Juniperus, 4th edn. Trafford Publishing, Bloomington

Ahani H, Jalilvand H, Hosseini-Nasr SM, Soltani KH, Ghazi MR, Mohammadzadeh H (2013) Reproduction of Juniperus polycarpos in Khorasan Razavi, Iran. For Sci Pract 15:231-237

Akkol EK, Guvenc A, Yesilada E (2009) A comparative study on the antinociceptive and anti-inflammatory activities of five Juniperus taxa. J Ethnopharmacol 125:330-336

Baskin CC, Baskin JM (1998) Seeds: ecology, biogeography, and evolution of dormancy and germination. Academic Press, San Diego 
Daneshvar A, Tigabu M, Karimidoost A, Farhadi M, Oden PC (2014) Growth characteristics and reproductive output of dwarf mistletoeinfected Juniperus polycarpos in Iran. J For Res 25:827-834

Demelash L, Tigabu M, Oden PC (2002) Separation of empty and dead-filled seeds from a seed lot of Pinus patula with IDS technique. Seed Sci Technol 30:677-681

Demelash L, Tigabu M, Odén PC (2003) Enhancing germinability of Schinus molle L. seed lot from Ethiopia with specific gravity and IDS techniques. New For 26:33-41

Djavanshir K (1974) Problem of regeneration of Juniperus polycarpos C. Koch in the forest of Iran. Silvae Genet 23:106-108

Downie B, Wang BSP (1992) Upgrading germinability and vigour of jack pine, lodgepole pine, and white spruce by the IDS technique. Can J For Res 22:1124-1131

Falleri E, Pacella R (1997) Applying the IDS method to remove empty seeds in Platanus $\times$ acerifolia. Can J For Res 27:1311-1315

Farjon A (2005) A monograph of Cupressaceae and Sciadopitys. Royal Botanic Gardens Press, Kew

Gutterman Y (2000) Maternal effects on seeds during development. In: Fenner M (ed) Seeds: the ecology of regeneration in plant communities, 2nd edn. CABI Publishing, Wallingford, pp 59-84

Himanen K, Nygren M (2015) Seed soak-sorting prior to sowing affects the size and quality of 1.5-year-old containerized Picea abies seedlings. Silva Fennica 49(3):14

International Seed Testing Association (2010) International Rules for Seed Testing. International Seed Testing Association, Bassersdorf

Kharazipour AR, Schöpper C, Muller C (2008) Review of forests, wood products and wood biotechnology of Iran and GermanyPart II. Universitätsverlag Göttingen, Göttingen

Khoushnevis M, Korouri SAA, Teimouri M, Matinizadeh M, Rahmani A, Shirvany A (2008) The effect of different treatments on rooting of Juniperus excelsa cutting. Iran J For Poplar Res 16:158-167

Korouri SAA, Khoushnevis M, Matinizadeh M (2012) Comprehensive studies of Juniperus species in Iran. Forest Range and Watershed Management Organization, Tehran (In Persian with English Abstract)
Mamo N, Mihretu M, Fekadu M, Tigabu M, Teketay D (2006) Variation in seed and germination characteristics among $J u$ niperus procera populations in Ethiopia. For Ecol Manag 225:320-327

Okasaka M, Takaishi Y, Kashiwada Y, Kodzhimatov OK, Ashurmetov O, Lin AJ, Consentino LM, Lee K-H (2006) Terpenoids from Juniperus polycarpos var. seravschanica. Phytochemistry 67:2635-2640

Pasquini NM, Defosse GE, Del Long O (2008) Upgrading germinability of Ponderosa pine seeds from Patagonia, Argentina by adjusting pre-chilling periods and applying the IDS technique. New For 36:93-102

Poulsen KM (1995) Application of the IDS-method to Pinus caribaea seed. Seed Sci Technol 23:269-275

Simak M (1981) Bortsortering av matat-dött frö ur ett fröparti (Removal of filled-dead seeds from a seed bulk). Sver Skogsvårdsförb Tidskr 5:31-36

Simak M (1984) A method for the removal of filled-dead seeds from a sample of Pinus contorta. Seed Sci Technol 12:767-775

Sivakumar V, Anandalakshmi R, Warrier RR, Singh BG, Tigabu M, Odén PC (2007) Petroleum flotation technique upgrades the germinability of Casuarina equisetifolia seed lots. New For 34:281-291

Slobodník B, Gutternberger H (2000) Ovule, megaspores and female gametophyte formation in Larix decidua Mill. (Pinaceae). Acta Biol Cracoviens Ser Bot 42:93-100

Sweeney JD, El-Kassaby A, Taylor DW, Edwards DGW, Miller GE (1991) Applying the IDS method to remove seeds infested with the seed chalcid, Megastigmus spermotrophus Wachtl, in Douglas-fir, Pseudotsuga menziesii (Mirb.) Franco. New For 5:327-334

Wulff RD (1995) Environmental maternal effects on seed quality and germination. In: Kigel J, Galili G (eds) Seed development and germination. Marcel Dekker Inc., New York/Basel/Hong Kong, pp 491-505

Zar J (1996) Biostatistical analysis, 3rd edn. Prentice-Hall Inc., Upper Saddle River 